\title{
Severe sepsis admitted through the emergency department to an internal medicine ward: time to antibiotic and its factors (retrospective cohort study)
}

\author{
J Pires*, L Ledo, G Jesus, F Ferreira, V Santos, C Madaleno, RMM Victorino, SM Fernandes \\ From ESICM LIVES 2015 \\ Berlin, Germany. 3-7 October 2015
}

\section{Intr/Objectives}

Sepsis mortality is determined by the time since hospital admission until antibiotic prescription. We aimed to evaluate the time until first antibiotic administration in patients with severe sepsis admitted directly to an Internal Medicine Ward and the factors that influence it.

\section{Methods}

We performed a retrospective study of patients discharged from an Internal Medicine Ward with severe sepsis diagnosis between January 2011 and December 2012. Time was counted since emergency department admission. Patients on exclusive palliative care were excluded.

\section{Results}

We identified 75 patients admitted with severe sepsis, with an average age of $75.7 \pm 13$ years, and an overall hospital mortality of $47 \%$. The patients included had in average 3 severity criteria, mainly acute kidney injury (67\%), altered state of consciousness (51\%), hypotension (56\%), and lactate above $36 \mathrm{mg} / \mathrm{dL}$ (34\%). Only $31 \%$ of the patients received antibiotic treatment in the first 3 hours (mean time since hospital admission until antibiotic administration: $8.0 \pm 7.9$ hours). The only factor associated with timely antibiotic administration was patient direct reference to reanimation room (Odds ratio: 5.0; $\mathrm{p}<0.01$ ). Importantly, age, gender, and the presence of comorbidities like cardiovascular disease, cancer or dementia was not related with time until first antibiotic prescription. Moreover, the presence of classic signs of systemic inflammatory response syndrome was also not related with rapid antibiotic prescription.

\section{Conclusions}

Understanding the factors for antibiotic delay is of utmost important to improve healthcare of severe sepsis patients. We call attention for the importance of rapid identification of these patients at the time of nurse triage in order to guarantee antibiotic administration in the first three hours. Premature nurse recognition of such patients seems to have a relevant role and therefore their training must be highlighted.

Published: 1 October 2015

\section{References}

1. Angus DC, Linde-Zwirble WT, Lidicker J, Clermont G, Carcillo J, Pinsky MR: Epidemiology of severe sepsis in the United States: analysis of incidence, outcome, and associated costs of care. Crit Care Med 2001, 29(7):1303-10.

2. Lefrant J-Y, Muller L, Raillard A, et al: Reduction of the severe sepsis or septic shock associated mortality by reinforcement of the recommendations bundle: a multicenter study. Ann Fr Anesth Reanim 2010, 29(9):621-8.

\section{doi:10.1186/2197-425X-3-S1-A222}

Cite this article as: Pires et al:: Severe sepsis admitted through the emergency department to an internal medicine ward: time to antibiotic and its factors (retrospective cohort study). Intensive Care Medicine Experimental 2015 3(Suppl 1):A222. 